\title{
Large Supratentorial Cortical Ependymoma in a Child
}

\author{
Alaattin Yurt, MD; Mehmet Selçuki, MD; Ali Rıza Ertürk, MD and Ali Küpelioğlu, MD
}

$\mathrm{E}$

pendymomas are rare neuroectodermal tumors arising from ependymal cells of the ventricular system, choroid plexus, filum terminale, or central canal of the spinal cord. Ependymomas are relatively uncommon nervous system tumors, constituting $1.2 \%$ to $7.8 \%$ of all intracranial neoplasms or $2 \%$ to $6 \%$ of all gliomas. ${ }^{1-8}$ Extraventricular ependymomas are especially rare, and whereas they have definite ependymal morphology, their histogenesis remains uncertain. Some tumors may extend to the gray matter reaching the pial surface, but pure cortical ependymomas are uncommon. We have encountered a few pediatric cases of supratentorial cortical ependymoma in the English literature. ${ }^{1-10}$

We present a case of an 11-year-old boy with a large supratentorial cortical ependymoma with massive calcification and central cyst formation manifested as generalized convulsion.
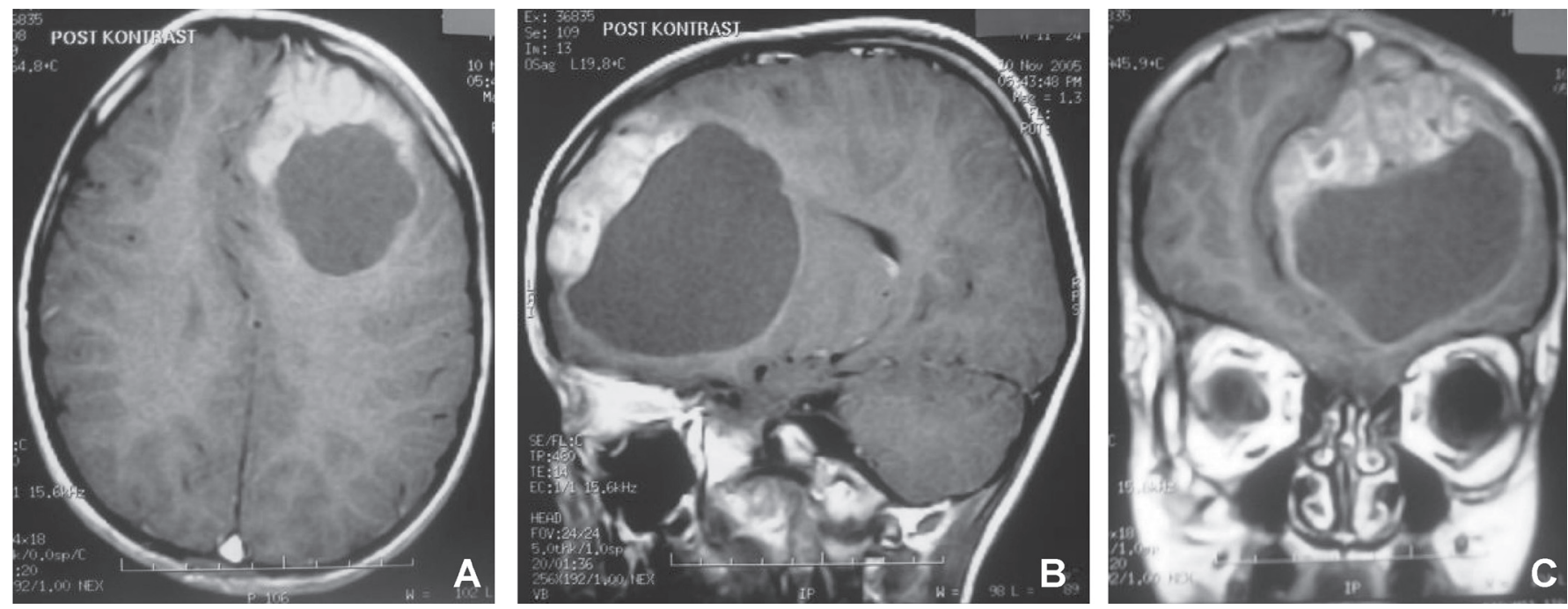

Figure 1. Preoperative axial, sagittal and coronal magnetic resonance images of the brain, showing a large left frontal cortical tumor associated with massive calcification and cyst formation.

Corresponding Author:

Alaattin Yurt, MD

123/4 Sokak No: 13 Kat 2, Daire 4

35350 Poligon / İzmir, Turkey

Tel: $+902322505050 / 5123$

Fax: $+9023226 \mid 4444$

Email: alayurt@superonline.com
Keywords: Child; Cortical; Ependymoma; Supratentorial

Received: July 29, 2009

Revised: October 10, 2009

Accepted: October 27, 2009

doi: $10.3121 / \mathrm{cmr} .2010 .877$

The Aperture, like the opening in the lens of a microscope that allows light to pass through, is a forum for art, humor, and images that provides a portal for new or different views of medicine and research. 

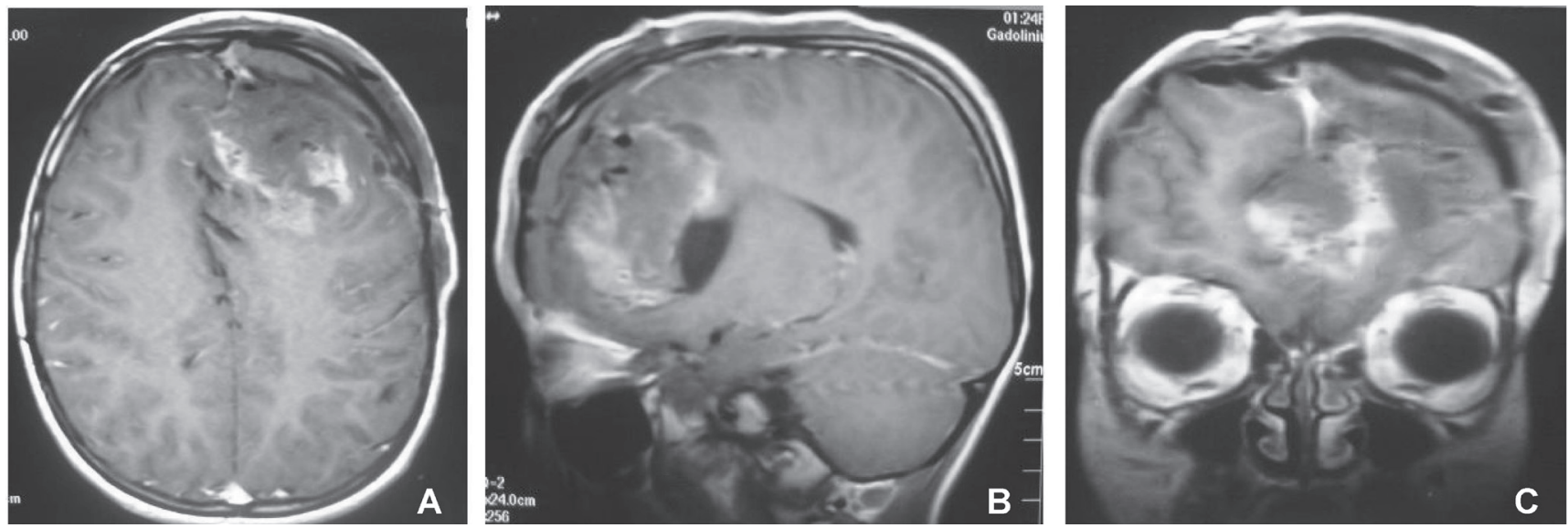

Figure 2. Postoperative axial, sagittal and coronal magnetic resonance images of the brain, showing the resection of the mass.

\section{Case Presentation}

An 11-year-old right-handed boy was admitted to our unit with complaints of headache, vomiting and generalized seizures. His systemic examination was normal. Neurological examination revealed bilateral papilledema. Routine laboratory investigations were normal. Computed tomography (CT) and magnetic resonance imaging (MRI) showed a large, poorly enhanced, left frontal mass with massive calcification and a central cyst (figure 1). Surgical resection of the mass was planned, and the patient underwent total resection of the tumor, which was located in the parenchyma with no dural attachment. The tumor was clearly demarcated and dissected subpially from the surrounding brain parenchyma. The surgical findings suggested no relationship with the lateral ventricular system. Histological examination of the tumor demonstrated perivascular pseudorosette formation and mitosis with massive calcification, and immunocytochemical positive reactivity for glial fibrillary acidic protein (GFAP) and epithelial membrane antigen, but not synaptophysin. These findings were compatible with ependymoma, World Health Organization grade 2. The patient's postoperative course was uneventful. He reported no complaints at his 3-month follow-up, and CT and MRI revealed no recurrence (figure 2). The patient was observed to be in good health 1 year after the operation.

\section{Discussion}

Ependymomas account for 3\% to $9 \%$ of all neuroepithelial tumors and, although occurring most often within the ventricular system, they may arise from the extraventricular parenchyma as well.1-5,7-10 Large supratentorial cortical ependymomas in children are a rarely seen pathological diagnosis. ${ }^{1-10}$ They represent the most frequent primary brain tumors after pilocytic astrocytomas and medulloblastomas. ${ }^{1-3,5,8}$ In patients under 20 years of age, approximately $60 \%$ of ependymomas arise in the infratentorium, or more specifically, in the fourth ventricle. ${ }^{1-5,8,10}$

The peak incidence occurs in the fourth and fifth decades, and $10 \%$ to $15 \%$ of the cases occurred in the first and second decades of life. ${ }^{1-6,8-10} \mathrm{~A}$ few pediatric cases of supratentorial cortical ependymoma have been reported in the English literature, ${ }^{1-10}$ but the clinical and pathological characteristics of supratentorial ependymomas in children are not well identified in the literature, because most series deal with ependymomas regardless of their location or age of the patient. Extraventricular ependymomas are especially rare, and whereas they have definite ependymal morphology, their histogenesis remains uncertain. Our patient shared several clinical features with previously published cases. ${ }^{3-6,8,9}$

Postoperative irradiation plays a role in the management of ependymomas, but indications for this adjuvant therapy remains a subject of debate. In recent studies of supratentorial ependymomas, it has been suggested that radiotherapy should be given to patients with anaplastic ependymomas, ${ }^{1-6,8,9}$ and in cases where only partial resection of either benign or malignant tumors has been achieved. ${ }^{1-5,7,8,10} \mathrm{~A}$ postoperative MRI with contrast has also been recommended for further evaluation of the extent of resection. ${ }^{3-5,7-10}$ Early second-look surgery may be proposed to achieve total excision in selected patients with accessible residual tumor detected on postoperative MRI.1-8 Therefore, reoperation to attempt complete tumor resection before initiation of radiotherapy should be considered. ${ }^{1,2,6,7,9,10}$ Chemotherapeutic agents have been tried, particularly in children for whom radiotherapy is contraindicated or in previously irradiated subjects with an inoperable tumor, but their benefit is still questionable. 1,2-5,7,9 The 5-year overall survival and recurrence-free survival rates were $55 \%$ and $37 \%$, respectively, and were highly affected by the extent of resection. ${ }^{1-4,7,9,10}$ Gender, histopathologic type, localization of the tumor, extent of surgery, postoperative radiotherapy, and chemotherapy influenced the prognosis. ${ }^{1-6,8,10}$

\section{Conclusion}

The importance of total removal is emphasized as ependymomas do not require adjuvant therapy such as radiotherapy or chemotherapy if there is total removal of the tumor. 


\section{References}

1. Afra D, Müller W, Slowik F, Wilcke O, Budka H, Turoczy L. Supratentorial lobar ependymomas: reports on the grading and survival periods in 80 cases, including 46 recurrences. Acta Neurochir (Wien) 1983;69:243-251.

2. Akyüz C, Emir S, Akalan N, Söylemezoğlu F, Kutluk T, Büyükpamukçu M. Intracranial ependymomas in childhood-a retrospective review of sixty-two children. Acta Oncol 2000;39:97-100.

3. Ehtesham M, Kabos P, Yong WH, Schievink WI, Black KL, Yu JS. Development of an intracranial ependymoma at the site of a pre-existing cavernous malformation. Surg Neurol 2003;60:80-82; discussion 83.

4. Molina OM, Colina JL, Luzardo GD, Mendez OE, Cardozo D, Velasquez HS, Cardozo JJ. Extraventricular cerebral anaplastic ependymomas. Surg Neurol 1999;51:630-635.

5. Roncaroli F, Consales A, Fioravanti A, Cenacchi G. Supratentorial cortical ependymoma: report of three cases. Neurosurgery 2005;57:E192; discussion E192.

6. Goodkin R, Zaias B, Michelsen WJ. Arteriovenous malformation and glioma: coexistent or sequential? Case report. J Neurosurg 1990;72:798-805.

7. Krieger AJ. A vascular malformation of the spinal cord in association with a cauda equina ependymoma. Vasc Surg 1972;6:167-172.

8. Ono S, Ichikawa T, Ono Y, Date I. Large supratentorial ectopic ependymoma with massive calcification and cyst formation - case report. Neurol Med Chir (Tokyo) 2004;44:424-428.

9. Pimentel J, Kepes JJ, Moura Nunes JF, Bentes C, Miguéns J, Antunes JL. Supratentorial giant cell ependymoma. Clin Neuropathol 2001;20:31-37.

10. Ernestus RI, Schröder R, Stützer H, Klug N. Prognostic relevance of localization and grading in intracranial ependymomas of childhood. Childs Nerv Syst 1996; $12: 522-526$

\section{Author Affiliations}

Alaattin Yurt, MD*; Mehmet Selçuki, MD广; Ali Rıza Ertürk, $M D^{*}$; Ali Küpelioğlu, $M D^{t}$

*Department of Neurosurgery, İmir Training and Research Hospital, İmir, Turkey

tDepartment of Neurosurgery, Kent Hospital, Izmir, Turkey Department of Pathology, Güneş Pathology Laboratory, İmir, Turkey 